\title{
UNIVERSITY OF LEEDS
}

This is a repository copy of Liminal Perceptions: Intermediality and the Exhibition of Nonfiction Film.

White Rose Research Online URL for this paper:

http://eprints.whiterose.ac.uk/109409/

Version: Accepted Version

\section{Proceedings Paper:}

Watkins, L (2018) Liminal Perceptions: Intermediality and the Exhibition of Nonfiction Film. In: Fossati, G, Lameris, BG, Jackson, V, Yumibe, J, Street, S and Rongen-Kaynakci, E, (eds.) The Colour Fantastic: Chromatic Worlds of Silent Cinema. Disorderly Order: Colours in Silent Film, 29-31 Mar 2016, Amsterdam, The Netherlands. Amsterdam University Press , Amsterdam, Netherlands , pp. 51-74. ISBN 9789462983014

(C) 2018, All authors / Amsterdam University Press B.V., Amsterdam. This is an author produced version of a paper published in The Colour Fantastic: Chromatic Worlds of Silent Cinema. Uploaded in accordance with the publisher's self-archiving policy.

\section{Reuse}

Items deposited in White Rose Research Online are protected by copyright, with all rights reserved unless indicated otherwise. They may be downloaded and/or printed for private study, or other acts as permitted by national copyright laws. The publisher or other rights holders may allow further reproduction and re-use of the full text version. This is indicated by the licence information on the White Rose Research Online record for the item.

\section{Takedown}

If you consider content in White Rose Research Online to be in breach of UK law, please notify us by emailing eprints@whiterose.ac.uk including the URL of the record and the reason for the withdrawal request. 
Liz Watkins, 'Liminal Perceptions: Intermediality and the Exhibition of Non-fiction Film' in The Colour Fantastic, In Victoria Jackson, Bregt Lameris, Sarah Street and Joshua Yumibe (eds) (Amsterdam University Press 2017).

\title{
Liminal Perceptions: Intermediality and the Exhibition of Non-fiction Film
}

\author{
Liz Watkins
}

\section{Liminal Colours}

The colours of early non-fiction films - although variously elusive in their photographic registration - were designed to be viewed sensuously. ${ }^{1}$ Colour, although complicated by the technical limits of photographic technologies, was a topic of concern for the scientific study of Antarctic wildlife, the landscape, and the chromatic effects of meteorological phenomena during the Heroic Age of Polar Exploration (1897-1922). The last decades of the nineteenth century saw the Royal Geographical Society invest in the lantern slide lecture as an educational model able to entice and entertain public interest: in popular exhibition, sensationalism and geography were already linked. ${ }^{2}$ Natural phenomena such as a flower opening or the uncertain movement of a storm at sea could offer an enchanting spectacle and as Gunning suggests, even in films with little narrative to discern, 'colour seems to function as an attraction, a very direct visual stimulus. It's something to look at, something to surprise you, to amaze you'. ${ }^{3}$ An analysis of the exhibition and performance of the photographic and cinematographic materials produced by Herbert G Ponting on Captain R F Scott's fated British Antarctic Expedition 1910-13 and in reference to Frank Hurley's work on Earnest Shackleton's Imperial Trans-Antarctic Expedition 1914-16 indicates that although colour eluded direct registration by any single medium (photography, film, sketches, watercolours, journals, meteorological notes), its recurrence in narratives and representations of the Antarctic for public exhibition is significant. Colour was evoked through the combination of media in 'synchronised lecture entertainments' as both a spectacle and as a 
referent in the depiction of landscape and the formation of narratives intended for public consumption. ${ }^{4}$

In expedition records notes on colour, although not a primary focus, do play a significant role in experimentation with photographic materials and in studying the landscape. The 'atemporal white space' of cartographic studies was gradually refigured in the public imaginary through photographic records as expeditions ventured further in to the Antarctic interior. ${ }^{5}$ In public exhibition, the abstract space imagined as a Great White Silence gradually became entwined with references to colour which form co-ordinates in the mapping of the interactions of body and environment; a record of the sensory perceptions, which becomes entangled with the broader discourse of spectacle and display in modern visual culture. The sensual appeal of a 'cinema of attraction' could convey, through description and varying combinations of media, what eluded direct representation: chroma, sound, touch, odour. ${ }^{6}$ The association of the body and its senses and perceptions of the landscape with spectacle in exhibition can be linked in records of the Aurora Australis, corona and halos that encircle the sun as the colour effects of light refracted by the ice, which the photographic technologies available to Ponting and Hurley had yet to register. ${ }^{7}$ Liminal colours - not directly registered, but signalled through a configuration of different media - trace a delicate combination of interests in the scientific study of landscape and its elaboration as spectacle, a balance that persists in the exhibition of early non-fiction film. ${ }^{8}$

The Royal Geographical Society founded their photography collection in 1884 as a resource for education and the promotion of exploration; the subsequent decades saw the illustrated lantern slide lecture became a popular form of entertainment. Ponting's work as camera artist for Scott's 1910-13 expedition was innovative in its inclusion of cinematography. As an experienced travel lecturer, Ponting was familiar with a dependence on visual media and its potential for conveying the work of an expedition. In scripting a 'cinema lecture' Ponting organised lantern slides and film into a form able to underscore selected aspects of written texts. ${ }^{9}$ Dixon finds a similar approach in his study of Frank Hurley's 'synchronised lecture entertainments' and observes that on return from Shackleton's 
expedition in 1916, Hurley attended four of Ponting's cinema lectures remarking on the aptitude of the camera artist in the performance of his work. ${ }^{10}$ Hurley comments that Ponting's 'manner and delivery is excellent', the lantern slide lectures forming combination of images and texts which 'gives the impression the penguins were actually performing to his words'. ${ }^{11}$ Hurley relates a day spent with Ponting discussing his work and the purchase of 80 lantern slides from Scott's expedition with rights to perform Ponting's lecture in Australia alongside the tale of his own work for Shackleton and Mawson. ${ }^{12}$

The documentation of the polar expeditions was a complex of scientific and artistic studies, producing materials that were then combined to form a narrative of their work and which were presented in multimedia forms. The narratives were elicited in performance from a complicated arrangement of photographs, the projection of film and lantern slides, guest speakers, artefacts, and live music. The scripts written by Ponting for his 'cinema lectures' relate the sonorous and chromatic qualities of the Antarctic landscape - the sound of conversation carried across a sparse icescape and the green lights of the Aurora Australis, tinged with red, moving across the sky, and the effects of light refracted by ice in to a spectrum of colours - and offer directions for text to be spoken only when the auditorium lights were dimmed. ${ }^{13}$ Captain Scott relates the 'vivid descriptions' given in Ponting's lantern slide lectures on board the expedition ship, the Terra Nova, as attentive to variations in sound and silence, colour, and movement: senses and perceptions that were not directly recorded by his photography. ${ }^{14}$ The integral, yet sublimated, role the body, its senses and perceptions colour, sounds, touch - in historiographies and media archaeologies of early 1900s expeditions were entwined with the encoding and interpretation of landscape. As a subject of study for the expedition and tempered by their indirect registration, such sensory perceptions are liminal to expedition records, yet they offer a vivid aspect of images and narratives of early 1900s Antarctic exploration. Liminal colours - interpreted from monochrome pencil notes, sketches, and photography - and recalled in performance are accessed and imagined in revisions of images and texts to nuance narratives and form a discourse on memory, expression, and sensation in early non-fiction film. 


\section{Ponting, Photography and Colour}

News reports published in 1910, prior to the departure of the expedition, indicate Ponting's plan to 'secure good colour effects of the Antarctic icescape by means of new autochrome cameras' ${ }^{15}$ and 'in true natural colours' ${ }^{16}$ Photography and the study of colour were integral to the identification of wildlife, but they were also intended to facilitate the notation of meteorological effects such as solar corona, paraselena (fig 1), iridescent cirrus clouds, and the refraction of colour by frozen crystals of water. The intention to record different effects of the light and atmospheric phenomena including that of the Aurora Australis is underscored by Ponting's handwritten notes: details of the time, date, and location signal the intersection of scientific study with an attention to the pictorial aesthetic of images required for lantern slide lectures. $[$ Place figure 1 and 2 here].

Scott's journal entries for September 1910 refer to the use of colour screens for still photography as 'an extraordinary addition to one's powers ${ }^{17}$ and comment that should Ponting be 'able to carry out the whole of his programme, we shall have a cinematograph and photographic record which will be absolutely new in expeditionary work'. ${ }^{18}$ Although the Aurora Australis (fig. 2) and parhelion had been observed and sketched by Edward Wilson on Scott's British National Antarctic Expedition 1901-04, descriptions of a display of the Aurora Australis over Mount Erebus trace the transience of colour and movement. Scott writes of a brightness across a 'curtain' of 'light $[\ldots]$ a palish green colour' which fluctuates with a distinctly a red flush preceding the motion of any bright part ${ }^{19}$; his reference to a 'green ghostly light' which 'seems suddenly to spring to life with rosy blushes', becomes a hypothesis playful with the idea of an infinite suggestion in this phenomenon [...] of life, form, colour, and movement never less than evanescent, mysterious - no reality $[\ldots]$ Remindful of superstition, provocative of imagination. Might not the inhabitants of some other world (Mars) controlling mighty forces thus 
surround our globe with fiery symbols, a golden writing which we have not the key to decipher? $?^{20}$

Scott's sense of wonder at the visual phenomena of the Antarctic landscape is tempered by the difficulties encountered by Ponting in producing a photographic record: a journal entry for 25 April 1911 notes that 'Ponting has taken some coloured pictures, but the result is not very satisfactory and the plates are much spotted' ${ }^{21}$ Descriptions of the Aurora Australis as fluvial sheets of light emphasise colour and movement as characteristics of the phenomenon which eluded direct photographic and cinematographic registration..$^{22}$ In a letter to Edward Wilson, Ponting expresses 'there are two regrets about the work I did. One is that I was unable to get any aurora pictures and the other that I was done out of the Western trip' ${ }^{23}$ The fleeting effects of these meteorological phenomena are recorded in retrospect through written accounts, sketches, and watercolours to be evoked through Ponting's curiously curatorial approach to the exhibition of still and moving images in his lantern slide lectures.

\section{Screening the Antarctic: Performance and Media}

The camera negatives of 1910-13 expedition were initially processed by Ponting in the Antarctic and returned to the UK in separate consignments to be screened in two parts under the title With Captain Scott R.N., to the South Pole (1911 and 1912). Ponting subsequently re-edited his film footage of the expedition across an initial twenty-year period leaving numerous prints in circulation including The Great White Silence (1924), which was coloured (tinting, toning, hand painting) and formed the focus of the British Film Institute National Archive's 2010 digital colour restoration. Ponting's subsequent revision, $90^{\circ}$ South (1933), was technological and textual, with the addition of synchronised sound and newly commissioned material (maps and animated sequences to illustrate the progression of the Southern Sledge journey). Ponting's correspondence with the Royal Geographical Society in 1917 indicates a performance of With Captain Scott to the Antarctic as a combination in which 'images, both moving and still can be projected at their best. The lecture lasts for two hours, and it is continuous series of pictures throughout. Many beautiful pictures will be 
presented for the first time, in addition to the main scenes that were originally shown' ${ }^{24}$ The film footage and selected photographs of the expedition were initially registered in black and white; in exhibition however, as with Hurley's work sections of film and lantern slides were coloured using tinting, toning and hand painting. ${ }^{25}$ The addition of colour to still and moving images may seem to introduce a layer of artifice in keeping with the entertainments of a 'cinema of attraction' and yet in Ponting's work the use of colour can be linked to his descriptive recollection of the chromatic effects of light refracted by ice in the Antarctic landscape.

Ponting's photographs and film footage of the Terra Nova seen through an ice-cave can be linked to his written account of the expedition, The Great White South through his attention to colour: 'During this first and subsequent visits, I found the colouring of the grotto changed with the position of the sun; thus sometimes green would predominate, then blue, and then again it was a delicate lilac'; a "myriad of crystals" that "decomposed the rays into lovely prismatic hues, so the walls appeared to be studded with gems". ${ }^{26}$ Ponting's script for With Captain Scott in the Antarctic includes lantern slides of this cavern in a section that emphasises the chromatic effect of light refracted by ice:

SLIDE 30 Interior of the cavern. Here it is. The entrance to it was fringed with great icicles and millions of ice crystals clustered about the walls. The sunlight reflected into these crystals was split up into all the colours of the prism, so that the walls gleamed as though they were covered with myriads of gems. The place was a veritable wonderland of beauty and it was the most remarkable work of Jack Frost that was seen during the expedition. This grotto was christened Aladdin's cave. ${ }^{27}$

The description of colour in the text and as an auditory register in the performance of the lantern slide lecture coalesces with the photographic in a combination of still and moving images to evoke the decomposition of the ice. Notes on changes in ice formations and sensory perceptions - odour, colours of refracted light, coldness - as sources of wonder, experienced anew in the extremes of the Antarctic landscape can be tracked across Ponting's cinema 
lecture script, recalled in his correspondence with other expedition members, and in his written account, The Great White South. A similar practice is encountered in The Great White Silence (Ponting, 1924) as still images of the cavern taken a year apart are intercut with sections of film (Fig 3). The curation of images and text into a lecture utilises practices that resonate with photographic effects of the film: from the sequencing of lantern slides and moving images that Ponting likens to time lapse photography - a shorthand for the duration of change such as that used to show a penguin chick hatching - to the manipulation of auditorium lights and sequences that 'must be run slower than usual' for dramatic effect. ${ }^{28}$

\section{[Place figure 3 here]}

Dixon's analysis of Hurley's travel lectures finds that the interconnections of written and visual media trace a 'presentational aesthetic, the collage and the dissolve' in a process of 'synchronisation' for exhibition that incorporates special effects that are associated specifically with photographic technologies. ${ }^{29}$ In Ponting's work this interrelatedness of image and text can be traced most vividly in his attention to colour and sound as sensory perceptions integral to his narration of the expedition. Hurley's attention to colour echoes that of Ponting, his diaries noting the refraction of light in the southern skies of Antarctica as 'prismatic, with a faint blue horizon blending into a pink tint in which stood a silver moon, glowing like a halo' before 'the horned moon dipped below the horizon, a faint orange blush suffused its path, which broadened and glowed till dawn spread the sky with tints of pink and blue' ${ }^{30}$ For Ponting these visual effects interwoven with the dramatic potential of theatrical lighting, seen in the exhibition notes of his cinema lecture, With Captain Scott, which signal words to 'speak in the dark' and to be followed by a series of slides dedicated to the effects of light on cirrus clouds. ${ }^{31}$ These slides are purposeful in their elaboration of colour:

Slide 35 'When the daylight is beginning to fail there are frequently the most beautiful cloud effects to be seen. There were the most remarkable "cirrus" clouds that any member of the expedition had ever observed in any part of the world, they were stained all pink by the afterglow, and looked exactly like flames. ${ }^{32}$ 
These descriptions, like the use of applied colour for selected lantern slides, photographic prints and film, offer a layer of interpretation over the 'subtle shadows of the snow and [...] wonderful transparent texture' that Scott notes of Ponting's black and white photography. ${ }^{33}$ The chromatic is not directly registered, but always encountered through recollection, revealing a layer of interpretation: the liminal colours of the landscape and transient effects of meteorological phenomena emerge through the intermedial practices of representation. Colour recurs in relation to a combination of natural and artificial light in a subsequent image labelled 'Slide 38 Fish Trap' which details the work of the expedition drawing fish to the surface in the darkness of the long polar night. Ponting remarks that the photograph of Atkinson and Clissold in $-45 \mathrm{~F}$ was taken by flashlight. A glass lantern slide held at the Royal Geographical Society is in keeping with this image and its annotation - 'Taking in Fish Trap' ${ }^{34}$ Yellow dye is hand painted across a select area of the photographic composition signifying light falling from a lantern set on the ice (fig 4), a use of colour that again visualises the description in Ponting's lecture.[Place Figure 4 here]

As a camera artist, Ponting's notes on the exhibition of his photography are exemplary, indicating the perceptions that remain beyond the technical limits of direct registration for the expedition records. Sound and its silences are noted as integral to a spatial sense of the Antarctic underscoring the imaged expanse of the landscape:

the prospect that opened out was of arresting grandeur $[\ldots]$ it was not so much the austere beauty of the scene that so dominated me, as its utter desolation, and its intense and wholly indescribable loneliness. I stood awhile beneath the shivering stars, with every sense alert, striving to detect some sound; but the stillness about me was profound. Concentrate the faculties as I might, I could hear nothing but the beating of my heart. ${ }^{35}$ Through silence Ponting finds the sonority of his body intense, other sounds that resonate across the vast landscape and distant voices are heard all the more acutely. For his lecture, With Captain Scott in the Antarctic, Ponting writes that 'in these lonely regions. On a calm day human voices in ordinary conversation can be heard a mile or more' and 'whales 
breathing at a distance of seven or eight miles away'. ${ }^{36}$ The phenomena of the landscape - its desolation marked in contrast with sensory perceptions such as the 'spray and a very oily odour' of the whales - interlink sensationalism and geography in exhibition. ${ }^{37}$ The 'ability to show something' is in Tom Gunning's sense a characteristic of the cinema of attractions that connects technologies and subject matter in a visual display, which is formulated to elicit a sensual response from the spectator. ${ }^{38}$

Ponting's lantern slides emphasise colour and display in performance, including what can be read as a reflexive note regarding the practice of exhibiting work from his earlier travel photography on board the Terra Nova. A lantern slide of Ponting lecturing appears to be a combination of images: a smaller imprint of a Japanese woman seated and holding a musical instrument is superimposed on to a picture of a blank screen set before a group of expedition members. The combination of two photographic negatives produces a single image (fig 5) which visualises Ponting's narration of his lectures in the Antarctic. ${ }^{39}$ This lantern slide 'Herbert G Ponting Lecturing' - held at the Royal Geographical Society is hand painted (fig 6): the expedition members are in dull blue and grey-brown colours, which with the darkness of the room frames the image that Ponting is seen projecting on to the screen. The cone of light cast from the projector is sketched in translucent layers of white directing the viewer's attention toward the picture superimposed on to the screen: the image of a woman that forms the focus of display is coloured in pinks, yellows, and bright blue against a pale sky-blue background. The composition of the image and the use of colour contrast emphasise a link between the chromatic and spectacle, which connects with photographic technologies as both the subject of his images and texts. ${ }^{40}$ [Place Fig 5 and 6 here]

\section{Notes about Colour}

The 1914 exhibition of With Captain Scott in the Antarctic at the Philharmonic Hall in London included a display of photographic prints. The practice of combining different media to convey a perception of the landscape that was not directly recorded, included plans to exhibit Ponting's photographic prints alongside sketches and watercolours by the 
expedition's Chief of Scientific Staff, Edward Wilson. In a letter of instruction regarding a package of one hundred watercolours that were returned to England in 1911, Wilson wrote that 'Ponting and I should exhibit together, an arrangement I like, especially if the exhibition comes off when we all return [...] If Ponting thinks that the colour in my things would in the least help his beautiful photos, then I should like them to be shown' ${ }^{41}$ Wilson articulates the potential of the watercolours to supplement the photographic record of the landscape by visualising through a combination of materials the colour effects that were otherwise lost from direct registration in the Antarctic. The execution of the paintings, like the photographs, was tempered by its technical limits: 'as regards colour one can do nothing out of doors. Chalks are possible but impracticable', thus his work was marked by the freezing of his hands, recovered 'again and again and at last produced an untidy and dirty but truthful rough sketch with notes scribbled all over it' to facilitate the reproduction of a coloured image (figure 7). ${ }^{42}$ The extremes of this practice are highlighted in the catalogue for an exhibition that combined Wilson's sketches and watercolours: 'owing to the very low temperature it was impossible to use water colours out of doors in the Antarctic. Dr Wilson therefore made careful pencil notes of the outlines and colour of hills and clouds' ${ }^{43}$ [Place Figure 7 Here] Wilson's sketchbooks from Southern Sledge Journey include pencil 'note sketches' made from direct observation and 'memory sketches' drawn from recollection; each annotates geographical features and meteorological effects with references to colour, orientation and date. ${ }^{44}$ Wilson's sketches privilege tonal values - the line and form of the landscape as an aesthetic of objective practice, over an attention to hue as a more subjective record - an approach that is in keeping with his study of The Elements of Drawing during the expedition. ${ }^{45}$ The delicate outline of a horizon sketched across two pages occasionally continues on a third, the connecting features marked by a symbol like a cross in an act of mapping the terrain. The notes on colour regard the appearance of rocks protruding from the ice and the halo and ghosting effects that encircle the sun (parhelion) and the moon (paraselene). Wilson's observations, as his practice adapts to the effects of working in an adverse environment, initially seem to accord to the history of artistic practice in Western 
culture that associates colore with artifice and subordinates it to the objectivity and logic that are linked in disegno (drawing). ${ }^{46}$ In differentiating disegno from colore in his practice, Wilson remarks upon the significance of the fleeting effects of light refracted by clouds of ice crystals and the formations that encase the morphology of the Antarctic. Wilson finds that the seemingly superficial effects of light disallow a general approach to sketching a landscape 'which is gone as you look at it [and] which you will never see again. Cloud. Sunset lights' necessitate attention to the 'small differences of shade [and] colour which make up all the contours of a place like this. ${ }^{47}$ Working between science and artistic practice, it seems that for Wilson, colore is integral to noting the physics and wonder of the environment. Colour for Wilson remains an uncertain yet significant characteristic in the perception of the landscape, obfuscating and mediating landmarks in an environment that continually alters.

The history of colour as an 'amalgam of theories and practices' can be tracked through the intermedial processes of recording and exhibiting images of the Antarctic. ${ }^{48}$ The study of colour traces a borderline of the interactions of body and environment represented in narratives and visual records of the landscape, recalled from a configuration of notes, sketches, and photographs. In this instance the annotation and later addition of colour to sketches and film, as Gunning notes, leaves it to 'shimmer on top of things [...] this kind of weird insubstantial quality [...] is part of its joy in the silent era' ${ }^{49}$ In the exhibition of early 1900s non-fiction film, applied colours utilised by Ponting are embedded in a discourse of memory and interpretation in the representation of Antarctic landscape, a process of mapping and understanding that persists in the formulation of materials for public display.

In this instance, applied colours, which Gunning suggests do not 'necessarily carry any decodable meaning, any paraphrasable meaning, but is purely a kind of sensuous play' indicate the intersections of body, technology, and environment that are particular to the combination of interests found in the work of the expedition members, from the scientific study of landscape to its elaboration as a narrative, education, and entertainment in exhibition. ${ }^{50}$ The intermedial and performative contexts of early cinema see colour take on a 'lyrical' ${ }^{51}$ or expressive function that diverges from the subordination of applied colouring 
within 'the dominant discourse on color cinema [which] subsumes its aesthetics to the telos of realism and privileges the development of natural color cinematography. Applied coloring has been denigrated in this logic as a primitive attempt to simulate reality before technology evolved enough to reproduce the indexical hues of reality' ${ }^{52}$ The liminality of colour in landscape, is linked in exhibition with spectacle and geography as the cultural ordering of an unfamiliar territory -visualised as an abstract and 'atemporal white space ${ }^{53}$ - its mediation and expression for a Western audience; the fleeting effects of colour express the temporality of the landscape.

The combination of different media and texts and the manipulation of specific images gradually forms an iconography of the explorer which is translated across different institutional and commercial domains ${ }^{54}$ Ponting's articulation of the body and landscape are integral to the expedition narrative, from the superimposition of a figure to exemplify the daunting scale of a mountain, to a written description of a sense of vulnerability against the amorphous glacial formations that emerge and deteriorate as temperatures alter. Ponting reviewed and re-edited the film footage over a period of 20 years in keeping with technical developments, from the incorporation of intertitles, newly commissioned film of dioramas, a visual effect of the sun rising after months of darkness in the Antarctic winter, and an animation of the Southern Sledge Journey for The Great White Silence (1924). ${ }^{55}$ A synchronised sound version of the film, $90^{\circ}$ South was produced in 1933. In correspondence with Frank Debenham, a geographer on the expedition, regarding a map of the region that was to be edited in to $90^{\circ}$ South, Ponting notes his decision to omit information that is 'only of interest to scientists' whilst exaggerating the scale of Mount Erebus to offer 'a remarkable idea of the kind of terrain in which the expedition operated' ${ }^{56}$ This compromise in accuracy marks the continuation of Ponting's interest in linking sensationalism and geography through a combination of media, performance and narrative. Ponting's revisions are in keeping with a gradual and discontinuous shift from the 'cinema of attractions' as a display of curiosities linking spectacle with natural phenomena to one of 'narrative integration' in which experiment and fascination with film form were subordinate to character and story. ${ }^{57}$ 
However, the organisation of still and moving images in the script for Ponting's cinema lecture With Captain Scott in the Antarctic appears to underpin the structure of his feature film The Great White Silence (1924): select visual effects are retained and the fascination with the chromatic manifests through instructions for colouring the film using fourteen different combinations of hand painting, tinting and, toning. ${ }^{58}$

The legacy of the intermedial contexts of the cinema lecture persist in the configuration of materials that form Ponting's 1924 film. The spectacular aspects of the landscape are evoked, not in 'natural colour', but through a combination of intertitles and applied colours, which signal the occurrence of fleeting effects of light on ice. Scott's reference to the 'Arch Berg', a particular formation of ice seen in an iconic image of the expedition ship, the Terra Nova, is particularly attentive to colour:

Ponting has been ravished by a view of the ship seen from a big cave in an ice berg, and wished to get pictures of it [...] I had rarely seen anything more beautiful than this cave. It was really a sort of crevasse in a tilted berg parallel to the original surface; the strata on either side had bent outwards; through the back the sky could be seen through a screen of beautiful icicles - it looked a royal purple, whether by contrast with the blue of the cavern or whether from an optical illusion I do not know. Through the large entrance could be seen also partly through icicles, the ship, the Western Mountains, and a lilac sky; a wonderfully beautiful picture. ${ }^{59}$

The lantern slide and notes on colour, which formed a focus for Ponting's Cinema Lecture are articulated in The Great White Silence to track the deterioration of the ice across a series of still and moving images. ${ }^{60}$ Ponting describes the Arch Berg as an 'ice grotto' and 'Aladdin's Cave', a territorial act in the naming of an uninhabited region. The interpretation of the landscape through a cultural reference is interwoven with the colour and framing of the image. The intersections of technology and landscape in representation are then typified in the image of the explorers departing on the Southern Sledge Journey and as their silhouettes are gradually eroded by a landscape of light and ice. In this image, photographic effects, 
cinematography, icon, and medium converge. The visual erosion of a detailed image composition becomes legible on a more affective level as it aligns geography and spectacle in an iconography of exploration and the unknown; the irresolute loss of the expedition members - Scott, Wilson, Oates, Evans and Bowers - on their return journey from the South Pole.

Liminal colours - through their indirect registration and as a focus of recollection in performance - link memory and expression with sensationalism in the interpretation of the landscape forming a discourse on geography in which colour, between nature and artifice, indicates a historical gaze that is inflected with imperial acts of naming and remapping the work of earlier expeditions and in response to the shifting morphology of the Antarctic. The colour effects of metereological phenomena and variations in light - sunrise, sunset, the months of darkness that characterise Antarctic winters incurring the use of flashlight photography - are associated with the temporality of the region. These environmental changes are, in turn, signalled by shifts in colour in The Great White Silence. The flashlight photography focuses on the work of the expedition - raising fish traps, meteorology, Ponting in his darkroom, Wilson painting, and Scott writing at his desk - the fall of light visualising the enclosed spaces of inhabitation. The use of this technique for exterior shots is organised around specific features of the landscape where an uneven circumference of artificial flash of light is quickly dispersed into the environment. Ponting's assertion that 'it's only the pictorial prints that pay ${ }^{61}$ coalesces with the use of the superimposition of a more dramatic sky or a figure to emphasise the desolation of the glacial plains as forms of interpretation and a move toward public exhibition. ${ }^{62}$ The intonation of colour can be tracked through the cultural organisation of images and texts - from the architectural description of the Arch Berg, also named as an Aladdin's Cave and Ice Grotto to the reference to the 'Charlie Chaplin' of the penguin colony - which embed the film in a context of commercialism, education, imperialism and entertainment through the organisation of a symbolic landscape. ${ }^{63}$

\section{Acknowledgements}


This research forms part of a British Academy project. With thanks to the British Film Institute National Archive, Thomas H. Manning Polar Archive, the Royal Geographical Society, and The Alexander Turnbull Library.

\section{References}

The Times, Saturday, $28^{\text {th }}$ May 1910), 8.

Otago Daily Times, issue 17892, 24 March 1920

'Captain Scott's Men. Science with the Camera. Terra Nova's Start Tomorrow'. Daily Mail, 31 May 1910. MS1453/39/1-2 Thomas H. Manning Polar Archive, Cambridge.

Dixon, Robert. Photography, Early Cinema and Colonial Modernity: Frank Hurley's Synchronized Lecture Entertainments. Anthem Press: Blackfriars, London, 2013.

— 'What was Travel Writing? Frank Hurley and the Media Contexts of Early Twentieth-Century Australian Travel Writing'. Studies in Travel Writing 11 (2007): 59-81.

Exhibition Catalogue. City of Hull Municipal Art Gallery, 1914.

Gage, John. Colour and Culture, Practice and Meaning from Antiquity to Abstraction.

Thames and Hudson, 1993.

Gunning, Tom, ‘A Slippery Topic: Colour as Metaphor, Intention or Attraction?’ In

Disorderly Order: Colours in Silent Film, edited by Daan Hertogs and Nico de Klerk, 39-47, 39. Amsterdam: Stichting Nederlands Filmmuseum, 1996).

-D.W. Griffith and the Origins of American Narrative Film: The Early Years at Biograph. Urbana and Chicago: University of Illinois, 1991.

— 'The Cinema of Attraction: Early Film, Its Spectator, and the Avant-garde'. Wide Angle 8.3/4 (1986): 63-70.

Huntford, Roland. 'Introduction' in Herbert G. Ponting, The Great White South. New York: Cooper Square [1921] 2000, i-xii. 
Hurley, Frank. The Diaries of Frank Hurley 1912-1941, edited by Robert Dixon and Christopher Lee. London: Anthem Press 2011.

Klein, Adrian Bernard. Colour-Music, the Art of Light. London: C. Lockwood, 1926. Lichtenstein, Jacqueline. The Eloquence of Color, Rhetoric and Painting in the French Classical Age. Translated by Emily McVarish. Berkeley, Los Angeles and Oxford: University of California Press, [1989] 1993.

Loiperdinger, Martin. 'Missing Believed Lost: The Film Narrator, Then and Now'. In Performing New Media 1890-1915, edited by Kaveh Askari, Scott Curtis, Frank Gray, Louis Pelletier, Tami Williams, and Joshua Yumibe, 87-94. John Libbey Publishing 2014.

Millar, Pat. 'A Person Separate: H.G Ponting - Photographer on Scott's last Expedition'. The Polar Journal 1, no. 1 (2011): 76-86.

Mundy, Rob. 'Pioneering Antarctic Photography: Herbert Ponting and Frank Hurley', The Polar Journal 4, no. 2 (2014), 389-406.

Peterson, Jennifer. 'Lyrical Education: Music and Colour in Early Non-fiction Film'. In Performing New Media 1890-1915, edited by Kaveh Askari, Scott Curtis, Frank Gray, Louis Pelletier, Tami Williams, and Joshua Yumibe, 186-192. John Libbey Publishing 2014.

Ponting, Herbert G. Letters, Thomas H Manning Polar Archive, Scott Polar Research Institute, University of Cambridge.

—. British Antarctic Expedition 1910-13, vol.7, MS/280/28/7

—. Letter to E A Wilson (27 October 1912), MS964/12; D

—. Letter to Mr R. Hinks, Royal Geographical Society (7 December 1917), MS 964/10/6

—. Letter to Apsley Cherry Garrard (17 December 1917), MS559/102/2

—. Letter to Frank Debenham (15 June 1926)

—. Letter to Frank Debenham (30 October 1931)

—. Letter to Frank Debenham (20 May 1933)

—. Letter to Frank Debenham (15 August 1933) 
Ponting, Herbert G. 'Mr Herbert G. Ponting's Cinema Lecture “With Captain Scott in the Antarctic”', MS-papers-1225, Alexander Turnbull Library, National Library of New Zealand.

- With Captain Scott in the Antarctic, Animal and Bird Life in the South Polar Regions, cinema programme, Eph-B-Antarctica (1914), PR-08-0409, Alexander Turnbull Library, National Library of New Zealand.

—. Lantern Slide Collection, Royal Geographical Society, RGS-IBG, LS/834.

—. The Great White South, (New York: Cooper Square [1921] 2000)).

—. The Great White Silence, cinema theatre programme, The Bournemouth Electric 11 August 1924: 8 .

Ruskin, John. The Elements of Drawing; in three Letters to Beginners. London: Smith, Elder \& co., 1857.

Scott, Robert Falcon. Journals, Captain Scott's Last Expedition. Edited by Max Jones. Oxford: Oxford University Press, 2006.

Street, Sarah, and Josh Yumibe. 'The Temporalities of Intermediality: Colour in Cinema and Arts of the 1920s'. Early Popular Visual Culture 11, no. 2 (2013): 140-157.

Watkins, Liz. 'Herbert G. Ponting's Materials and Texts'. In Color and the Moving Image: History, Theory, Aesthetics, Archive, edited by Simon Brown, Sarah Street, Liz Watkins, 230-242. Routledge; New York and London, 2013.

Wilson, Edward A. Captain Scott's British South Pole Expedition 1910-13, Catalogue of an Exhibition of Antarctic Sketches \& Water Colours, Drawings of Norwegian and Swiss Scenery etc., City of Hull Municipal Art Gallery, April 1914.

Wilson, Edward A, Southern Sledge Journey - sketchbooks (1911-12) MS797/1-2;

BJ, Thomas H Manning Polar Archive, University of Cambridge.

—. Wilson, Edward A. Letter to Mr and Mrs R J Smith $19^{\text {th }}$ October 1911, MS.559/142/9

Thomas H Manning Polar Archive, University of Cambridge. 
—. Wilson, Edward A. Lecture Notes 1910-13, MS1225/3, Thomas H Manning Polar Archive, University of Cambridge.

Yumibe, Joshua. 'Colour as Performance in Visual Music, Film Tinting and Digital Painting'. In Performing New Media 1890-1915, edited by Kaveh Askari, Scott Curtis, Frank Gray, Louis Pelletier, Tami Williams, and Joshua Yumibe, 293-302. John Libbey Publishing 2014.

Yumibe, Joshua. Moving Color: Early Film, Mass Culture, Modernism. New Brunswick, New Jersey and London: Rutgers University Press, 2012.

${ }^{1}$ Joshua Yumibe, Moving Color: Early Film, Mass Culture, Modernism (New Brunswick, New Jersey and London: Rutgers University Press, 2012); Jennifer Peterson, 'Lyrical Education: Music and Colour in Early Non-fiction Film,' in Performing New Media 18901915, ed. Kaveh Askari, Scott Curtis, Frank Gray, Louis Pelletier, Tami Williams, and Joshua Yumibe (John Libbey Publishing 2014), 186-192.

${ }^{2}$ Robert Dixon, 'What was Travel Writing? Frank Hurley and the Media Contexts of Early Twentieth-Century Australian Travel Writing', Studies in Travel Writing 11 (2007): 59-60. ${ }^{3}$ Tom Gunning, 'A Slippery Topic: Colour as Metaphor, Intention or Attraction?' in Disorderly Order: Colours in Silent Film, ed. Daan Hertogs and Nico de Klerk (Amsterdam: Stichting Nederlands Filmmuseum, 1996), 40-41. Colour in such films can be linked to transient effects such as flowers opening, fountains, fireworks, sunrises and sunsets in landscapes that were new to the cinematographer in travel films.

${ }^{4}$ Dixon, 'What was Travel Writing?' 59, 63.

${ }^{5}$ Kathryn Yusoff, 'Configuring the Field: Photography in Early Twentieth-Century Antarctic Exploration' in New Spaces of Exploration: Geographies of Discovery in the Twentieth 
Century, ed. Simon Naylor and James R. Ryan (London and New York: I B Tauris, 2010), $52-77,72$.

${ }^{6}$ Yumibe, Moving Color, 9; Adrian Bernard Klein, Colour-Music, the Art of Light (London:

C. Lockwood, 1926). The broader cultural context of public entertainment in which travel films were seen included experimentation with the chromatic traversed the theatrical use of light projected through coloured gels on to the diaphanous materials of a performer's costume, musical instruments that projected a variation of coloured light according to a chromatic score and the elaboration of landscapes in the production of lantern slides using applied colours (tinting, toning, hand painting)

${ }^{7}$ Tom Gunning, 'The Cinema of Attraction: Early Film, Its Spectator, and the Avant-garde', Wide Angle 8.3/4 (1986): 63-70.

${ }^{8}$ Yumibe, Moving Color, 6; Sarah Street and Josh Yumibe, 'The Temporalities of Intermediality: Colour in Cinema and Arts of the 1920s', Early Popular Visual Culture 11, no. 2 (2013): 140-157.

${ }^{9}$ Herbert G. Ponting, 'Mr Herbert G. Ponting's Cinema Lecture "With Captain Scott in the Antarctic"', MS-papers-1225, Alexander Turnbull Library, National Library of New Zealand; Liz Watkins, 'Herbert G. Ponting's Materials and Texts', Color and the Moving Image: History, Theory, Aesthetics, Archive, ed. Simon Brown, Sarah Street, Liz Watkins (Routledge; New York and London, 2013), 230-242. Ponting's film footage and lantern slides were in circulation from 1911. Although Ponting held the rights to the expedition stillsphotography, it was not until 1914 that the Gaumont Company agreed to his purchase of his cinematographic records. Ponting briefly began a programme of cinema lectures, incorporating still and moving images, at the Philharmonic Hall in London, which was discontinued with outbreak of the Great War. In 1918 Hurley purchased rights to exhibit the lantern slide lecture in Australia. With Scott to the Scott to the South Pole was screened with a lecture by Walter Searle in Dunedin in New Zealand in 1920 (Otago Daily Times 24 March 1920). Ponting resumed his lecture programme in 1919 whilst planning to reedit the material 
into a cinematic feature The Great White Silence (1924). The Great White Silence (1924) was exhibited internationally including France, Germany including Holland.

${ }^{10}$ Dixon, 'What was Travel Writing?' 59, 63. Frank Hurley, The Diaries of Frank Hurley 1912-1941, ed. Robert Dixon and Christopher Lee (London: Anthem Press 2011), 107.

${ }^{11}$ Hurley, Diaries, 18 November 1916.

${ }^{12}$ Hurley, Diaries, 28 July 1918. On the 3rd August 1918 Ponting accompanied Hurley to Fenchurch Street Station as he departed for Tilbury Docks. In 1918 Hurley negotiated the Australasian exhibition rights for a combination of three films: The Home of the Blizzard (Hurley, 1913) which was based on Douglas Mawson's Australasian Antarctic Expedition 1911-14, In the Grip of the Polar Pack Ice (Hurley, 1917) from Shackleton's 1914-16 expedition, alongside Ponting's With Captain Scott in the Antarctic (Dixon 2007; Hurley, Diaries, $17^{\text {th }}$ July 1918).

${ }^{13}$ Ponting, Cinema Lecture, MS-papers-1225.

${ }^{14}$ Robert Falcon Scott, Journals, Captain Scott's Last Expedition, ed. Max Jones (Oxford: Oxford University Press, 2006),1910-11; Herbert G. Ponting, The Great White South (New York: Cooper Square [1921] 2000)).

15 'Captain Scott's Men. Science with the Camera. Terra Nova's Start Tomorrow', Daily Mail, 31 May 1910, MS1453/39/1-2 Thomas H. Manning Polar Archive, Cambridge.

${ }^{16}$ The Times, Saturday, $28^{\text {th }}$ May 1910, 8.

${ }^{17}$ Scott, Journals, 287.

${ }^{18}$ Scott, Journals, 293.

${ }^{19}$ Scott, Journals, 200.

${ }^{20}$ Scott, Journals, 200

${ }^{21}$ Scott, Journals, 178.

22 The expedition meteorologist, George Simpson, refers to Professor Störmer's photographs of the Aurora Borealis in Norway, but does not suggest that these images were in colour (Scott, Journals, 200). 
${ }^{23}$ Ponting, Letter to E. A. Wilson (27 October 1912), MS964/12; D. Edward A. Wilson was Chief of Scientific Staff and a zoologist on the British Antarctic Expedition 1910-13. Ponting returned to England in 1912 and continued writing to Wilson and Scott prior to news of the fate of the Southern Sledge Party reaching the UK in 1913. The Western journey was to Cape Crozier to collect Emperor Penguin eggs.

${ }^{24}$ Ponting, Letter to Mr R. Hinks, Royal Geographical Society (7 December 1917), MS 964/10/6; Ponting, Cinema Lecture, MS-papers-1225. The duration of the lecture noted in Ponting's letter to the Royal Geographical Society (1917) corresponds with 'cinema lecture' script, which is held in the Alexander Turnbull library in New Zealand. The script is undated, its title resembles that of the 1911-12 screenings, yet it narrates the fate of the expedition, news of which reached England in 1913. Ponting purchased the film negatives from the Gaumont Company in 1914 and is listed as copyright holder of the cinema lecture script (MSpapers-1225). The two hour duration of Ponting's cinema lecture script corresponds to that of his 1924 film, The Great White Silence. The organisation of still and moving images in the Cinema Lecture script is not identical to and yet underpins the form of the 1924 release.

${ }^{25}$ Dixon, 'What was Travel Writing?' 66.

${ }^{26}$ Ponting, Great White South, 68.

${ }^{27}$ Ponting, Cinema Lecture, MS-papers-1225, 35.

${ }^{28}$ Ponting, Cinema Lecture, MS-papers-1225, 40 and 16.

${ }^{29}$ Dixon, 'What was Travel Writing?' 66.

${ }^{30}$ Hurley, Diaries, 23, 39.

${ }^{31}$ Ponting, Cinema Lecture, MS-papers-1225, 44.

${ }^{32}$ Ponting, Cinema Lecture, MS-papers-1225, 44.

${ }^{33}$ Robert Falcon Scott cited in Ponting, The Great White South, xv.

${ }^{34}$ Herbert G. Ponting, Lantern Slide Collection, Royal Geographical Society, RGS-IBG, LS/834/77. This collection of lantern slides was purchased by the Royal Geographical Society from Ponting's estate in 1936 following his death in 1935. The collection includes more items 
than the 80 lantern slides purchased by Hurley in 1918 or the 85 listed in Ponting cinema lecture script, although the latter does include 'interval slides'.

${ }^{35}$ Ponting, Great White South, 149-150.

${ }^{36}$ Ponting, Cinema Lecture, MS-papers-1225, 17.

${ }^{37}$ Ponting, Cinema Lecture, MS-papers-1225, 17.

${ }^{38}$ Gunning, 'Cinema of Attraction', 64 and 66; Dixon, 'What was Travel Writing?' 66.

${ }^{39}$ Ponting, Cinema Lecture, MS-papers-1225, 49. Ponting, Lantern Slides, RGS-IBG, LS

834/96. Ponting, The Great White South, 135. The caption for this image in Ponting's written account of his work on the expedition indicates this process of editing images into an illustration 'The Author Lecturing on Japan (A Composite Photograph).'

${ }^{40}$ Ponting refers to the use of flashlight photography and includes images of himself filming and photographing his own endeavours as well as those the other members of the expedition. ${ }^{41}$ Edward A.Wilson, Letter to Mr and Mrs R J Smith, $19^{\text {th }}$ October 1911, MS.559/142/9 Thomas H Manning Polar Archive, University of Cambridge.

${ }^{42}$ Wilson, Lecture Notes 1910-13, MS1225/3, Thomas H Manning Polar Archive, University of Cambridge.

${ }^{43}$ Exhibition Catalogue, City of Hull Municipal Art Gallery, 1914.

${ }^{44}$ Wilson, Southern Sledge Journey - sketchbooks (1911-12) MS797/1-2; BJ, Thomas H Manning Polar Archive, University of Cambridge.

${ }^{45}$ John Ruskin, The Elements of Drawing; in three Letters to Beginners (London: Smith, Elder \& co., 1857); Wilson, Lecture Notes 1910-11, MS1225/3.

${ }^{46}$ Jacqueline Lichtenstein, The Eloquence of Color, Rhetoric and Painting in the French Classical Age, trans. Emily McVarish (Berkeley, Los Angeles and Oxford: University of California Press, [1989] 1993),5-6.

${ }^{47}$ Wilson, Lecture Notes 1910-11, MS1225/3.

${ }^{48}$ John Gage, Colour and Culture, Practice and Meaning from Antiquity to Abstraction (Thames and Hudson, 1993), 8 
${ }^{49}$ Gunning, 'A Slippery Topic', 40.

${ }^{50}$ Gunning, 'A Slippery Topic', 41.

${ }^{51}$ Peterson, 'Lyrical Education', 186.

${ }^{52}$ Yumibe, Moving Color, 6.

${ }^{53}$ Yusoff, 'Configuring the Field', 72.

${ }^{54}$ Dixon, 'What was Travel Writing?' 61.

${ }^{55}$ Watkins, 'Materials and Texts', 230-242.

${ }^{56}$ Ponting, Letters to Frank Debenham, 20 May 1933; 30 October 1931; 15 August 1933, $\mathrm{MS} / 280 / 28 / 7$.

${ }^{57}$ Gunning, Tom, D.W. Griffith and the Origins of American Narrative Film: The Early Years at Biograph (Urbana and Chicago: University of Illinois, 1991).

${ }^{58}$ Watkins, 'Materials and Texts', 230-242.

${ }^{59}$ Scott, Journals, 75.

${ }^{60}$ Ponting, Cinema Lecture, MS-papers-1225, 35.

${ }^{61}$ Ponting, Letter, 17 December 1913, MS559/102/2.

${ }^{62}$ The superimposition of two negatives, one of a storm swept sky and the second of a figure traversing an expanse of ice by sledge, is evident of images held at the Scott Polar Research Institute, Cambridge: Glass plate negative P2005/5/606, November 1911 and a variation P2005/5/1554, 1911.

${ }^{63}$ Watkins, 'Materials and Texts', 230-233. 